\title{
A NOVA RAZÃO DO DIREITO DO TRABALHO: UMA ANÁLISE DOS INDICADORES JURÍDICOS E SOCIAIS DA REFORMA TRABALHISTA NA FRANÇA
}

\section{The new reason of the labour law: a analysis of the legal and social data relating to labour reform in France}

Selma Cristina Silva de Jesus (UFBA)

Douglas Mota Oliveira (UFBA)

Informações do artigo

Recebido em 08/08/2019

Aceito em 09/10/2019

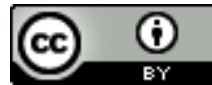

Esta obra está licenciada com uma Licença Creative Commons Atribuição 4.0 Internacional.

\section{Como ser citado (modelo ABNT)}

JESUS, Selma Cristina Silva de; OLIVEIRA, Douglas Mota. A nova razão do direito do trabalho: uma análise dos indicadores jurídicos e sociais da reforma trabalhista na França. Cadernos do CEAS: Revista Crítica de

Humanidades. Salvador, n. 248, set./dez., p. 713-741, 2019. DOI: https://doi.org/10.25247/2447$861 X .2019 . n 248 . p 713-741$

\begin{abstract}
Resumo
O presente artigo pretende, inicialmente, analisar as recentes mudanças na legislação trabalhista francesa (principalmente as duas últimas reformas ocorridas em 2016 e 2017), dando ênfase às inovações legislativas relacionadas aos seguintes aspectos: contratação, jornada de trabalho, saúde e segurança no trabalho, instâncias de representação de pessoal e negociação coletiva.

Posteriormente, busca-se apresentar algumas implicações das inovações legislativas sobre a dinâmica do trabalho e emprego na França. O texto é composto por três partes principais, além da introdução e considerações finais. Na primeira parte, aborda-se a relação entre a consolidação da razão neoliberal e a busca incessante pelo estabelecimento de um novo marco legal das relações de trabalho na França. Em seguida, apresenta-se uma sistematização das inovações legislativas relacionadas à jornada de trabalho, contratação, saúde e segurança e negociação coletiva. Por fim, são analisados alguns efeitos destas mudanças sobre a dinâmica do trabalho e emprego na França. Dessa forma, procura-se demonstrar como as alterações no marco legal trabalhista refletem a consolidação do neoliberalismo como sistema de governo e que requer, de forma correlata, a conformação de uma nova racionalidade para o Direito do Trabalho, consentânea com o ethos de uma sociedade fundada na concorrência e no paradigma do homem-empresa.
\end{abstract}

Palavras-chave: Neoliberalismo. Direito do Trabalho. Reforma Trabalhista. França.

\section{Abstract}

The present paper intends, initially, to analyze the recent changes in the French labor legislation (specially, the last two reforms occurred in 2016 and 2017), emphasizing the legislative innovations related to the following aspects: hiring, working hours, health and safety at work., instances of staff representation and collective bargaining. Subsequently, it seeks to present some implications of legislative innovations on the dynamics of work and employment in France. The text is structured in three main parts, besides the introduction and concluding remarks. The first part deals with the relationship between the consolidation of neoliberal reason and the relentless pursuit of establishing a new legal framework for labor relations in France. The following is a systematization of legislative innovations related to working hours, hiring, health and safety and collective bargaining. Finally, some effects of these changes on the dynamics of work and employment in France are analyzed. Thus, it is intended to demonstrate how changes in the legal labor framework reflect the consolidation of neoliberalism as a system of government and that, in a correlative way, requires the conformation of a new rationality for labor law, consistent with the ethos of a society founded on competition and the human-enterprise paradigm.

Keywords: Neoliberalism. Labor law. Labor reform. France. 


\section{Introdução}

A França, a partir da década de 1970, iniciou um processo de flexibilização da legislação trabalhista, que se deu ora pormeio de mudanças pontuais no Código de Trabalho Francês, ora através de reformas cujo objetivo era o estabelecimento de um novo marco legal das relações de trabalho. De um modo geral, na exposição de motivos para a realização das reformas trabalhistas francesas, destacam-se os seguintes argumentos: i) necessidade de manter a atratividade de investimentos de empresas nacionais e internacionais em um contexto acirrado de concorrência entre diversos países; ii) as alterações da legislação trabalhista foram (e são) concebidas como a principal via de enfrentamento do desemprego; iii) era preciso dar mais autonomia às empresas para modular diversos aspectos das relações de trabalho (como, por exemplo, jornada de trabalho e o regime de admissão e demissão de trabalhadores) por meio da ampliação da negociação em detrimento da legislação; iv) diminuir a segmentação e heterogeneidade no mercado de trabalho francês (EYDOUX; FRETEL, 2016; SCHÖMANN, 2015).

Embora a origem desta busca pelo estabelecimento de um novo marco legal das relações de trabalho esteja vinculada à emergência de um novo padrão de desenvolvimento do capitalismo - designado por Harvey (1992) de acumulação flexível -, verifica-se, a partir da crise de 2008, um novo impulso no desmonte dos direitos trabalhistas em vários países da Europa e América Latina, tais como: Itália, Espanha, França, México, Brasil, etc. Essa "nova onda" de reformas trabalhistas é resultante do recrudescimento do neoliberalismo, entendido aqui, "como um conjunto de discursos, práticas e dispositivos que determinam um novo modo de governo sobre os homens segundo o princípio universal da concorrência" (DARDOT; LAVAL, 2016, p. 17). E uma das expressões deste novo modo de governo é justamente o desmonte dos direitos e dos mecanismos de proteção social.

Em consonância com a racionalidade neoliberal, no caso francês, deve-se considerar, ainda, que as propostas de reformas trabalhistas se dão no contexto de pressão exercida pela Troika ${ }^{1}$ para que os países da Zona do Euro adotassem medidas de austeridade. Assim, conforme Schömann (2015), ainda que alguns países da zona do euro tenham adotado tais 
medidas antes mesmo da crise de $2008^{2}$, a partir deste fato, a Comissão Europeia estabeleceu que a reforma radical da legislação trabalhista se constituía no principal meio de enfrentamento do desemprego na região.

O presente artigo visa, justamente, em um primeiro momento, analisar as recentes mudanças na legislação trabalhista francesa (principalmente as duas últimas reformas ocorridas em 2016 e 2017), dando ênfase às inovações legislativas relacionadas aos seguintes aspectos: contratação, jornada de trabalho, saúde e segurança no trabalho, instâncias de representação de pessoal e negociação coletiva. Posteriormente, busca-se apresentar algumas implicações das inovações legislativas sobre a dinâmica do trabalho e emprego na França. O texto é composto por três partes principais, além da introdução e das considerações finais. Na primeira parte, aborda-se a relação entre a consolidação da razão neoliberal e a busca incessante pelo estabelecimento de um novo marco legal das relações de trabalho na França. Em seguida, apresenta-se uma sistematização das inovações legislativas relacionadas à jornada de trabalho, contratação, instâncias de representação de pessoal, negociação coletiva, saúde e segurança no trabalho. Porfim, são analisados alguns efeitos destas mudanças sobre a dinâmica do trabalho e emprego na França.

\section{Neoliberalismo e reforma trabalhista na França}

Em A ética protestante e o espírito do capitalismo, Max Weber (1994) propõe-se demonstrar como a conformação histórica do modo de produção capitalista não prescindiu da estruturação de uma nova racionalidade, centrada numa ética vocacionada para o trabalho profissional, produtivo. Assim, Weber se distancia daquelas abordagens marxistas que explicam a gênese do capitalismo como resultado lógico-necessário do movimento de forças produtivas objetivas, independentes da consciência e da composição política que as representa em cada etapa de seu desenvolvimento.

De forma semelhante, para Pierre Dardot e Christian Laval (2016), o neoliberalismo não se constitui como a mera resposta a uma necessidade da acumulação capitalista, do movimento de estruturas econômicas anteriores e determinantes (numa relação de

\footnotetext{
${ }^{2}$ A Alemanha realizou a reforma da legislação do trabalho em 2003, por exemplo.
} 
causalidade) das formas de organização política e social: antes, apresenta-se como uma racionalidade própria, orientadora de comportamentos positivos nas relações interpessoais, em que o Estado, longe da posição absenteísta proposta pelo liberalismo clássico, desempenha um papel ativo na introdução e generalização do modelo concorrencial.

Desse modo, Dardot e Laval (2016) não restringem o neoliberalismo a sua dimensão econômica. Para os referidos autores, o neoliberalismo porta uma normatividade própria, instituidora da concorrência como padrão subjetivo presente em todas as esferas sociais e orientadoras da atuação de governantes e governados. O poder político centralizado no Estado desempenha, então, a função de introduzir normas legais e de comportamento que respondam ao ethos de uma sociedade cada vez mais competitiva e que transfere ao indivíduo a iniciativa e a responsabilidade sobre a gestão de sua vida e dos riscos que lhe são inerentes.

Também por isso, as dimensões política e jurídica, em vez de se reservarem à tarefa única de emoldurar relações econômicas predeterminadas, afiguram-se como agentes de constituição e dinamização dessas relações.

Tradicionalmente, afirma-se o fortalecimento histórico das teses neoliberais, sobretudo, a partir da crise do Estado do bem-estar social na década de 1970, articulada ao processo de transnacionalização do capital, seja no momento produtivo, pela socialização da produção no plano internacional; seja no momento da circulação/mercado, pela mobilidade internacional do capital financeiro. Com a recessão econômica que atingiu os países de capitalismo avançado, ganhariam força as defesas em torno da desregulamentação e da não ingerência do Estado na economia - portanto, de um retorno do discurso liberal ou de constituição de uma ideologia neoliberal.

Na França, de acordo com Laurent Willemez (2017), o maio de 1968 inaugurou um períod o de ofensiva do Direito do Trabalho, marcado pela conjunção do desenvolvimento de normas protetivas dos trabalhadores e da pressão do movimento social e sindical sobre os governantes, garantind o a conquista de novos direitos em face dos riscos sociais e a expansão do controle sindical sobre a direção da empresa. Desse modo, segundo o autor, até o início dos anos 1980, poucos aspectos da vida profissional dos empregados escapariam ao regramento estatal, o que acabaria por conferir ao Estado um papel, ao mesmo tempo, de regulador, protetore árbitro no bojo das contradições Capital XTrabalho. 
Ao longo das décadas de 1970 e 1980, porém, esse paradigma protetivo do Direito do Trabalho francês competiu com a proliferação de defesas em torno da reorientação do modelo de regulação do Trabalho, recentralizado na ótica da empresa, e engajado na criação de possibilidades jurídicas de flexibilização e precarização, o que definiria um novo quadro nas relações de emprego, marcado, sobretudo, pela emergência:

a) da pluralização das formas (atípicas) de contratação do trabalho por tempo determinado (Contrat à Durée Determiné- CDD), não obstante o reconhecimento do contrato de trabalho a tempo indeterminado (Contrat à Durée IndeterminéCDI) como forma típica/geral de contratação da força de trabalho;

b) da diversificação, ainda que no âmbito do contrat à durée indeterminé, dos instrumentos de contratação de força de trabalho - a exemplo do contrat à durée restreinte pour desmissions à l'exportation, dos contrats de chantier ou dos contrats intérimaire -, resultando na individualização das relações de trabalho;

c) da construção, no âmbito do Direito Coletivo do Trabalho, de estratégias de controle das demissões em massa por razões econômicas, que exigiriam consulta aos representantes dos trabalhadores - e que desembocariam, a partir de 2008, na ascensão de dispensas por razões econômicas mascaradas como dispensas por razões pessoais;

d) da redução do tempo de trabalho (reduction du temps du travail - RTT), realizada entre 1998 e 2001, que, embora comemorada como uma conquista em favor dos trabalhadores, se fez acompanharpela intensificação do trabalho, com ampliação dos riscos à saúde física e psíquica na relação de emprego;

e) da generalização da ideia de diálogo e negociação entre sindicatos e empresas, com o esvaziamento da ideia de greve do repertório de ação sindical, assim como de outras conflitualidades no âmbito das empresas;

f) da polarização, no âmbito acadêmico, entre duas concepções antagônicas de Direito do Trabalho: uma centrada na ideia de proteção ao trabalhador; outra, na de segurança jurídica e regulação como garantia de produtividade.

No entanto, essa disputa entre paradigmas do Direito do Trabalho na França não pode ser compreendida senão em conjunção com um processo maior de desenvolvimento da 
racionalidade neoliberal na Europa, que tem em seu cerne a edificação de um campo concorrencial continental e na figura da União Europeia - assim como na influência e correlação de forças exercidas sobre os Estados nacionais - um de seus principais agenciadores.

Com efeito, segundo Alain Supiot (2016), entre as condições apontadas para a desintegração da "Europa social", estão: a) a conformação do euro como moeda comum, enquanto fator de acirramento da concorrência internacional e, por conseguinte, de redução dos custos trabalhistas e ficais - e que resultou na constituição de um modelo ordoliberal materializado num sistema de bancos centrais europeus economicamente independentes e política e socialmente irresponsáveis; b) a global race, enquanto ideal quase darwinista de uma marcha universal em torno da competitividade, responsável pela construção de um paradigma internacional de desregulamentação do trabalho, e de esvaziamento da efetividade das no rmas internacionais de proteção aos trabalhadores, além de redimensionar o papel das cortes internacionais; c) a afirmação do Direito do Trabalho como obstáculo à realização do direito ao trabalho, isto é: a contraposição entre o patamar protetivo de regulação e a inevitabilidade do desemprego, à medida que se avolumavam defesas em tomo de uma reforma do código de trabalho.

É, contudo, a partir da crise econômica mundial de 2008, que essa racionalidade neoliberal é "radicalizada" em torno de uma reformulação do Direito do Trabalho mais consentânea com a autonomia da vontade e com a dinâmica negocial do direito privado e em face das instituições responsáveis pela regulação e fiscalização das relações laborais.

De acordo com Isabele Schömann (2015), após o ano de 2008, a União Europeia passoua apresentar a proposta de flexibilização e modernização do Direito do Trabalho nos países membros como a única resposta eficaz para a crise econômica e o desemprego.

Ainda, segundo a autora, em diversos dos Estados membros da União, as modificações na legislação trabalhista foram introduzidas ao arrepio das práticas democráticas regulares, sobretudo com a utilização de processos legislativos sumários, voltados a situações de urgência (2015, p. 10), de modo a inviabilizar a discussão e participação social na sua elaboração.

É neste sentido que as reformas trabalhistas promovidas na França, especialmente as suas últimas (ocorridas em 2016 e 2017) - se inserem num conjunto de medidas de austeridade recomendadas pela Troika aos Estados membros da UE, sendo a França, 
inclusive, um dos últimos países da União a adotar as alterações legislativas propostas (ARAÚJO; DUTRA; JESUS; 2018).

No caso da reforma trabalhista de 2016, observa-se que as alterações promovidas pela "El Khomri" (Lei no 2016-1088 de 08/08/2016), nomeada em referência à então Ministra do Trabalho de François Hollande, Myriam El Khomri, remetem à publicação do artigo "Pour une declaration des droits du travail", pelos juristas Robert Badinter e Antoine Lyon-Caen, em junho de 2015. As ideias defendidas por Badinter e Lyon-Caen foram seguidas pelo relatório Combrexelle de setembro de $2015^{3}$ e por um novo relatório publicado em janeiro de 2016, por uma comissão presidida pelo mesmo Robert Badinter ${ }^{4}$.

Eydoux e Fretel apontama participação ativa dos juristas na proposição de reformas ao código do trabalho, ao mesmo tempo em que ironizam como as propostas, bastante convergentes, partiam de um grupo reduzido de autores, relacionados entre si e com citações de uns aos outros (2016, p. 16). Pode-se entrever, dessa forma, uma estratégia voltada à criação de uma atmosfera social justificadora do caráter emergencial com que essas medidas seriam postas em discussão e aprovadas.

Em seu artigo, Badinter e Lyon-Caen (2015) atribuem os índices crescentes de desemprego na França dos últimos 40 anos à excessiva complexidade do Código de Trabalho francês, descrito como uma legislação "obesa", que não causaria senão confusão e preocupação entre os empregadores. Por essa razão, propuseram uma reforma integral do código, de modo a colocarà disposição de empregados e empregadores modelos de contrato de trabalho informatizados baseados em princípios claros e facilmente identificáveis - o que se realizaria com uma arquitetura legislativa estruturada em princípios gerais de ordem pública; previsão das possibilidades de negociação; e previsão das disposições aplicáveis na ausência de acordos (BADINTER; LYON-CAEN, 2015; ESPINA, 2016).

Um aspecto expressivo da introdução de uma nova racionalidade de regulação trabalhista por aquelas reformas está na inversão, introduzida pela El Khomri, da hierarquia normativa do Direito do Trabalho francês, sobrepondo o acordo coletivo de trabalho,

\footnotetext{
3 Disponível em:

http://www.strategie.gouv.fr/sites/strategie.gouv.fr/files/atoms/files/fs_rapport_missionjdc_08092015.pdf

4 Disponível em: https://www.humanite.fr/sites/default/files/conclusions-de-la-mission-de-robert-badintersur-les-principes-essentiels-du-droit-du-travail-.pdf
} 
resultado da negociação coletiva entre sindicatos e empregadores, às normas inscritas no Código do trabalho (ABAUZIT; FILOCHE, 2016, p. 148).

A seu turno, a lógica da prevalência do negociado sobre o legislado(sobreposição das normas resultantes da negociação coletiva sobre aquelas constantes do código) é ampliada com a eleição de Macron e a edição de suas cinco ordonnances- espécie legislativa editada pelo Conselho de Ministros e pendente de ratificação pelo parlamento - em acordo com o tom emergencial e democraticamente deficitário característico das inovações na legislação trabalhista dos países da UE, como denunciado por Schömann (2015).

As recentes modificações no marco regulatório das relações de trabalho na França refletem a pressão, capitalizada, sobretudo, pela Comissão Europeia, no sentido do desmonte do modelo social francês e da conformação, como explicitado por Álvaro Espina (2016), de um mercado de trabalho concorrencial comum na zona do Euro. Este projeto requer a positivação, no interior dos Estados membros, de um regramento trabalhista coerente com os mandamentos da agenda flexibilizante preconizada pela União Europeia como solução para os problemas da crise de 2008.

Ao mesmo tempo, sua realização não abre mão da articulação com agentes internos, aptos à produção do ambiente sociopolítico necessário à sua exposição como única resposta possível aos reclamos modernizantes da competição no plano internacional, à esquerda e à direita.

Ademais, a sua compreensão, inserida no bloco histórico de intervenções na legislação empregatícia des de os anos 1980, permite entrever os contornos do que seria essa nova racionalidade reguladora do trabalho, em que a função protetiva do Dir eito trabalhista é substituída pela de normatização, preocupada com a dinamização das relações produtivas, sem descuidar de garantir segurança jurídica ao empregador. E que se manifesta, seja no plano das relações individuais de trabalho, pela diversificação das formas de contratação, contribuindo para a atomização cada vez maior da experiência profissional do empregado (por conseguinte, construindo um ambiente de trabalho heterogêneo, que estimula a competitividade entre os trabalhadores e fragiliza as possibilidades de uma experiência coletiva); seja no plano das relações coletivas de trabalho, reduzindo o plano de ação das entidades de classe à negociação com o patronato, como via de flexibilização para a garantia do acesso/permanência no emprego. 
A seguir, analisamos as principais inovações legislativas relacionadas às formas de contratação, jornada de trabalho, saúde e segurança e negociação coletiva.

\section{Principais indicadores jurídicos das recentes reformas trabalhistas na França}

Esta seção apresenta as principais alterações da legislação trabalhista em relação às formas de contratação e demissão, jornada de trabalho, instâncias de representação de pessoal, saúde e segurança no trabalho e negociação coletiva. A sistematização apresentada aqui é resultante de uma pesquisa bibliográfica e documental sobre a temática. Ressalta-se que, na pesquisa documental, consultamos as leis que alteraram o código de trabalho na França, principalmente as duas últimas reformas de 2016 e 2017.

Formas de contratação e demissão

Desde os anos 1970, o Código de Trabalho francês vem admitindo novas formas de contratação, aumentando, assim, as possibilidades de alocação do trabalho. O processo de flexibilização das formas de contratação ocorreu, basicamente, através de três movimentos: (i) edição de novos tipos de contrato de trabalho; (ii) alteração das regras de contratos de trabalhojá existentes; (iii) mudanças nas regras de demissão.

No tocante à edição de novos contratos, verifica-se que, embora o contrato de trabalho portempo indeterminado (CDI) seja a forma normal e geral das relações de trabalho na França, a partir da década de 1970, criaram-se novas possibilidades de admissão da mãode-obra: o contrato de trabalho temporário (1972)5, o contrato de trabalho de duração determinada (1979), contrato de trabalho intermitente (2000), etc. A maioria destas novas possibilidades de contratações tem em comum o fato de terem um tempo limitado e

\footnotetext{
5 Trata-se de uma modalidade contratual na qual uma agência faz o recrutamento de um ou mais funcionários para trabalhar numa empresária usuária, por um tempo limitado e realizando uma tarefa específica. A utilização deste tipo de contrato só é possível nas seguintes situações: "substituição de um empregado ausente, substituição de um proprietário artesanal, substituição temporária de um gerente de fazenda, substituição de um empregado que tenha sido provisoriamente contratado a tempo parcial, aumento temporário da atividade comercial, emprego sazonal, enquanto aguarda por um empregado para assumir suas funções, aguardando a abolição definitiva do cargo de empregado que saiu definitivamente da empresa". Para maiores informações, ver https://www.service-public.fr/particuliers/vosdroits/F11215.
} 
possuírem regras mais flexíveis de demissão, quand o comparada s com o trabalho de duração indeterminada (CDI).

A partir dos anos 2000, são criados novos tipos de contratos de duração determinada $(C D D)$, contribuindo para um aumento do "cardápio" de opções contratuais à disposição do empregador. Deste modo instituiu-se o contrato de trabalho duração determinada a objeto definido $(2014)^{6}$ e o CDD jogador profissional (2015)7.Os contratos em CDD por terem um tempo limitado possuem regras mais flexíveis de demissão, quando comparados com as regras de demissão dos trabalhadores em CDI.

A reforma trabalhista de 2017 impactou os contratos do tipo CDD e CTT ao permitir que os seguintes aspectos fossem definidos por negociação coletiva: i) duração total do contrato; ii) número máximo de renovações possíveis; iii) métodos de cálculo do período de espera em caso de contratos sucessivos. A referida reforma alterou, ainda, a sanção prevista para o empregador que descumpra a obrigação de apresentar por escrito o contrato de trabalho de duração determinada no prazo máximo de 2 dias úteis após a contratação de um funcionário. Antes da reforma, o descumprimento desta norma resultava na requalificação automática do CDD em CDI. Após a reforma, a sanção prevista para o descumprimento da norma citada acima é uma indenização de um mês de salário. Por fim, a reforma trabalhista de 2017 reduziu o prazo de contestação de uma ruptura antecipada dos contratos CDD e CTT, que passou do período de 2 anos para 1 ano.

Ainda no que concerne ao movimento de edição de novos contratos, convém destacar a criação de novos tipos de contrato de duração indeterminada: i) contrato intermitente; ii) contrato de missão para exportação ${ }^{8}$; iii) contrato de chantier ${ }^{9}$. Vale ressaltar que o contrato intermitente foi criado em 2000 com a edição da Lei Aubry. Esta modalidade contratual permite alternar períodos trabalhados e não trabalhados, de acordo com a necessidade do contratante (empregador). Contudo, diferentemente do Brasil, a utilização do contrato de

\footnotetext{
6 Para maiores detalhes, ver Lei n. 2014-1545 de 20/12/2014. O CDD a objeto definido é um tipo de contrato específico para engenheiros e gerentes.

7 Este contrato teve por objetivo regulamentar as contratações no mundo esportivo.

8 O contrat de mission à l'exportation é um tipo de contrato de trabalho de duração indeterminada com regras de demissão/ruptura do contrato mais flexíveis. Esta modalidade contratual foi concebida para o desenvolvimento das exportações de uma empresa.

9 O contrato de chantier é um tipo de contrato de trabalho por tempo indeterminado, específico para o setor da construção civil. Esse tipo de contrato tem regras mais flexíveis de demissão do que o CDI clássico.
} 
trabalho intermitente é restrita a alguns setores caracterizados por atividades sazonais, tais como: shows, ritmos escolares, ciclos sazonais e turismo.

A reforma trabalhista de 2016 estabeleceu uma diferença entre disposições relativas à ordem pública, que não podem ser derrogadas por meio de negociação (seja acordo de empresa ou negociação coletiva), e, por outro lado, as que estão sujeitas à negociação. $\mathrm{Na}$ reforma, algumas disposições relativas ao trabalho intermitente foram enquadradas como de natureza pública e não pod em ser alteradas por negociação, a saber: para que um contrato de trabalho intermitente seja utilizado por uma empresa é necessário que esta modalidade contratual seja aprovada por um acordo de empresa (exceto na situação relatada abaixo), ou na falta deste, por uma convenção coletiva. O empregador não pode, por iniciativa própria, proporao empregado sercontratado sob tal modalidade.

Em fase de experimentação (até 31/dezembro/2019), a contratação para empregos sazonais cujas atividades são repetidas anualmente em períodos mais ou menos fixos ou ao ritmo das estações - como as colheitas - pode ser feita sem acordo por empresa ou convenção coletiva de trabalho. Não precisam, também, de convenções ou acordos de empresas as "empresas adaptadas"10 e os "centros de distribuição de trabalho". Porfim, destaca-se que a utilização do contrato de trabalho intermitente para a substituição de trabalhadores em greve ou para efetuar trabalhos insalubres é proibida na França.

As reformas de 2016 e 2017 alteraram as regras de demissão. A demissão de um empregado contratad o portempo indeterminado só é permitida na existência de uma causa real e séria, seja esta causa motivada por razões pessoais ou econômicas. A ausência de comprovação desta causa (seja por motivos econômicos ou pessoais) resulta em sanções por demissão injustificada. Em 2016, a Lei El Khomri estabeleceu que, em caso de comprovação de dificuldade econômica, uma empresa pode demitir um funcionário. Neste caso, a evidência da dificuldade econômica se daria pela demonstração da diminuição dos pedidos e dos números de negócios da empresa em relação ao ano anterior. $\mathrm{E}$, em caso das empresas com menos de onze funcionários, uma queda dos negócios em relação ao último semestre satisfaz a condição necessária para que a empresa utilize o dispositivo de demissão por razões

\footnotetext{
${ }^{10}$ As "empresas adaptadas" (Entrepriseadaptée), cujo gênero não existe no Brasil, são aquelas previstas no Artigo L5213-13 do Código do Trabalho francês que se constituem em força de trabalho de pelo menos $80 \%$ dos trabalhadores com deficiência, habilitados para o mercado de trabalho.
} 
econômicas. E, por fim, ainda sobre esta modalidade de demissão, a reforma trabalhista de 2016, permite que as empresas demitam em caso de adoção de mudanças organizacionais necessárias para alavancar a competitividade das empresas.

Em 2017, flexibilizam-se ainda mais as regras para ruptura do contrato de trabalho por meio da instituição de que a não comprovação dos motivos da demissão (sejam eles de ordem pessoal ou econômica) não mais resultaria na requalificação da demissão como sem justa causa (ou sem causa real e séria). Sobre esta questão, a reforma estabeleceu que o empregador pode, por iniciativa própria ou por demanda do trabalhador, informar/precisar os motivos da demissão, e a ausência de precisão do motivo da demissão resultaria, agora, apenas em uma indenização que não pode exceder a um mês de salário.

Em relação às demissões por motivos econômicos, a reforma de 2017 estabelece que, através de um acordo de empresa, um empregadorpode fazer uso de um plano de demissão voluntária para dispensar seus funcionários - plano este designado de ruptura convencional coletiva. No tocante à demissão por justa causa, a reforma trabalhista de 2017 estabeleceu um teto para as sanções pecuniárias atribuídas pela Justiça em caso de demissão abusiva (ou seja, quando o empregador não comprova a causa da demissão). Por meio desta reforma, ficou estabelecida, ainda, uma redução do prazo de contestação na Justiça da demissão abusiva, que passou de 2 anos para 1 ano.

Jornada de trabalho

Na França, as sucessivas reformas legislativas sobre jornada de trabalho foram realizadas com intuito de permitir uma maior subordinação jurídica dos trabalhadores às necessidades das empresas, tal como aborda Michel Miné (2017). Segundo o referido autor, a análise das inovações legislativas neste campo revela um duplo movimento: de um lado, há um movimento pela redução da jornada legal de trabalho; e, de outra parte, há uma flexibilização das possibilidades de ajustes na jornada de trabalho, levando a um aumento da jornada efetiva de trabalho dos trabalhadores em tempo integral por meio da crescente utilização das horas suplementares.

Em consonância com o movimento apontado acima, em 1982, na presidência de François Miterrand, a jornada semanal de trabalho foi reduzida para 39 horas (por meio da Ordonnance n. 82-41, de 16 de janeiro de 1982). A fixação da jornada em 39 horas era vista 
pelo governo como primeiro passo para o estabelecimento dajornada semanal de 35 horas, que deveria ocorrer antes de 31 de dezembro de 1985 (MINÉ, 2017). Em contrapartida a esta redução da jornada, visando contemplar as demandas dos empregadores, a Ordonnance n. 82-41 institui a possibilidade de modulação do tempo do trabalho por meio da negociação coletiva. Esta modulação da jornada de trabalho poderia ser feita por meio "acordos depreciativos", classificados desta forma em razão da possibilidade de os acordos coletivos serem menos favoráveis do que a lei para os funcionários.

Em 1998, ocorreu a edição da Lei Aubry I n. 98-461, proposta pelo ministro Lionel Jospin, que fixou novamente a jornada semanal de trabalho em 35 horas. A Lei Aubry II de 19 de janeiro de 2000 confirmou a nova duração legal da jornada de trabalho em 35 horas semanais (ou 1600 horas anuais). Paralelamente à redução da jornada de trabalho, a Lei em tela estabeleceu um dispositivo de assistência permanente às empresas, que se fundiu com a redução das contribuições sociais sobre os salários. A referida assistência não estava mais vinculada a nenhum método de contagem do tempo. Desse modo, as pausas, feriados ou tempo de treinamento, que antigamente eram contabilizados como "tempo de trabalho real", a partir da entrada em vigor da Lei podem ser desconsiderados. Ademais, para ter acesso à assistência permanente não há nenhuma contrapartida para as empresas em temos de empregos criados ou preservados. Registra-se, ainda, que o benefício da assistência permanente está sujeito à negociação coletiva (seja acord o coletivo ou acordo por empresa).

Observamos que, em paralelo à redução da jornada (mencionada acima), coloca-se em marcha um movimento de ampliação do tempo de trabalho pormeio do aumento das horas extras ou suplementares. O decreto de 15/10/2002 de François Fillon (ministro do trabalho) é exemplar deste tipo de movimento, uma vez que aumentou o limite máximo de horas extras, passando de 130 horas anuais para 180 horas. Em 2004, este limite anual passou de 180 horas para 220 horas extras.

Em 2008, a lei n. 2008-789 autorizou a realização de ajustes na jornada de trabalho mediante convenção coletiva. E na reforma trabalhista de 2016 (lei n. 2016-1088), verificamos um aprofundamento da possibilidade de modulação do tempo de trabalho. Assim, a referida lei instituiu que, por meio de um acordo de empresa (e não apenas por convenção coletiva como previsto em 2008), era possível realizarajustes na jornada de trabalho.

A lei 2016-1088 (Lei El Khomri) reafirmou que a jornada legal de trabalho é de 35 horas em todos os setores da atividade econômica e o que passa disto deve ser contabilizado como 
horas suplementares. Considerando as horas suplementares, a referida lei estabelece que o tempo máximo da jornada semanal seja de 48 horas e, em casos excepcionais, pode chegar a 60 horas semanais (neste último caso é necessária a autorização da inspeção do trabalho). No artigo L. 3121-36 da lei em tela, define-se que, quando a jornada semanal for calculada em um período de 12 semanas consecutivas, o tempo desta não pode ultrapassar em média 44 horas por semana ou 46 horas/semana quando previsto em acordo por empresa ou convenção coletiva. Ainda sobre as horas suplementares (ou extras), a lei El Khomri prevê o pagamento de uma taxa de majoração de 25\% nas 8 primeiras horas e 50\% depois deste período (artigo L 3121-22). Contudo, existe a possibilidade de anulação desta regra mediante acordo de empresa ou convenção coletiva, desde que seja respeitado o piso de $10 \%$ de acréscimo à hora extra trabalhada.

Em 2017, as iniciativas de flexibilização do tempo de trabalho são aprofundadas. Desse modo, pormeio do artigo 4, da Ordonnance n²017-1386, de 22 de setembro de 2017, institui-se que, na ausência de acordo de empresa ou convenção coletiva (acordo de ramo/categoria): i) o contrato de trabalho pode fixara remuneração do tempo de pausa;ii) o contrato de trabalho pode estabelecercontrapartidas ao tempo gasto pelo trabalhadorpara vestir-se e despir-se mencionadas no artigo ; iii) essas contrapartidas podem ser determinadas pelo empregador após uma consulta ao comitê de empresa ou aos delegados de pessoal (na existência destes). Conforme o sindicato Força Obreira (2018), tais medidas introduzem dispositivos de individualização das relações contratuais.

As instâncias de representação de pessoal

Uma das principais premissas das reformas trabalhistas de 2016 e 2017 era a necessidade de ampliar o espaço de negociação. Argumentava-se que era preciso ampliaro diálogo social. Mas, contraditoriamente a esta premissa, em 2017, por meio da Ordonnance n. 2017-1386, há uma diminuição dos órgãos representativos de pessoal, reduzindo, desse modo, justamente as instâncias de diálogo nas empresas.

Assim, antes da referida reforma, havia três instâncias representativas de pessoal, a saber: (i) o Comitê de Empresa, composto por funcionários, delegados sindicais e empregador, que têm mandato de 4 anos. Esse comitê é obrigatório para empresas com pelo menos 50 empregados; (ii) Delegado de pessoal (DP) é uma instância representativa dos 
trabalhadores, obrigatória para as empresas de pelo menos 11 funcionários. O número de delegados varia em função do tamanho da empresa e estes têm horas destinadas ao exercício de suas funções na referida delegação; (iii) o Comitê de Higiene, Segurança e Condições de Trabalho (CHSCT), órgão obrigatório em empresas de pelo menos 50 empregados, composto por empregador (ou seu representante), funcionários das empresas designados pelos delegados de pessoal e representantes do Comitê de Empresa. Após a reforma, o Comitê Social e Econômico (CSE) substituirá os três órgãos mencionados acima, que deixarão de existirno mais tardar até $1 / 1 / 2020$.

O Comitê Social e Econômico (CSE) torna-se um órgão obrigatório para as empresas de pelo menos 11 funcionários. O CSE possui as seguintes atribuições: (i) apresentar ao empregador as reivindicações individuais ou coletivas relacionadas ao cumprimento do Código do Trabalho, salários, aplicação de acordos e convenções coletivas aplicáveis na empresa; (ii) atuar na promoção da saúde, segurança e melhora das condições de trabalho, além de investigaracidentes de trabalhos e a ocorrência de doenças ocupacionais; (iii) acionar a inspeção do trabalho para resolver problemas relacionadas ao descumprimento de disposições legais pela empresa. Ele é composto pelo empregador e representantes dos funcionários. Nas empresas de menos de 300 trabalhadores, é obrigatória a presença de um delegado sindical no CSE. E nas empresas com mais de 300 empregados, cada entidade sindical representativa dentro da empresa tem o direito de designar um membro para comporo CSE.

Saúde e segurança no trabalho

Conforme mencionado acima, a reforma trabalhista de 2017 substituiu três órgãos representativos de pessoal pelo CSE, dentre eles o Comitê de Higiene, Segurança e Condições de Trabalho (CHSCT). Assim, no lugar deste último, uma Comissão de Saúde, Segurança e Condições de Trabalho (CSSCT) deve ser criada no interior do Comitê Social e Econômico (CSE) em empresas de pelo menos 300 funcionários. No caso de empresas de 50 a 299 funcionários, que tenham ao menos uma instalação nuclear ou apresentem riscos de acidentes maiores (grande porte) e certos depósitos de minerais, é possível a instalação da CSSCT no interior do CSE desde que seja autorizada por um inspetor (fiscal) do trabalho. E 
nas empresas de 11 a 49 funcionários existirá apenas o Comitê Social e Econômico sem a Comissão de Saúde e Segurança e Condições do Trabalho no interior do referido Comitê.

Assim, após a reforma trabalhista de 2017, não haverá mais um órgão representativo de pessoal responsável exclusivamente pelas questões relacionadas à saúde e segurança. Tal medida está sendo questionada na Justiça pela Confederação Geral do Trabalho-Força Obreira (CGT-FO, 2018) por entender que a mesma fere o direito à saúde (consagrado na Constituição de 1946 e nas normas europeias e internacionais, das quais a França é signatária), além de colocar em xeque o princípio constitucional de igualdade entre todos, ao fazer uma distinção entre empresas com menos de 300 funcionários e as que têm 300 ou mais trabalhadores.

\section{Negociação coletiva}

Preliminarmente, antes de analisar as inovações legislativas referentes à negociação coletiva, é importante ter em vista as especificidades do modelo sindical francês em relação ao brasileiro, das quais a mais importante, talvez, seja o fato de que as relações coletivas de trabalho na França não estão limitadas pela regra da unicidade sindical - que impede a existência de mais do que uma entidade representativa da categoria porbase territorial ${ }^{11}$.

Segundo a definição do código do trabalho francês, os acordos de empresa (accord d'entreprise) designam aquelas negociações realizadas em nível da empresa ou do estabelecimento (L. 2235-5), ao passo que os acordos "de categoria" (convention de branche) referem-se a normas mais amplas, consubstanciadas em convenções coletivas, acordos de categoria, acordos profissionais e intercategorias (L. 2232-11). Por analogia, poderiam ser equiparados, respectivamente, ao acordo coletivo e à convenção coletiva do modelo brasileiro.

\footnotetext{
${ }^{11}$ Tradicionalmente, distingue-se entre a unicidade e a pluralidade sindicais como correspondendo, a primeira, ao modelo em que uma norma jurídica impede a existência de mais do que uma entidade representativa (regra do sindicato único), ao passo que, na segunda, essa norma não existe, permitindo a criação de entidades coexistentes, ainda que os trabalhadores decidam pela existência de um único sindicato ("unidade sindical") - seria o sistema de liberdade sindical plena, preconizada pela Convenção n 87 da OIT. No Brasil, prevalece a regra da unicidade desde a década de 1930, tendo sido mantida pela Constituição de 1988, ao impedir a existência de mais do que uma entidade sindical na mesma base territorial (DELGADO, 2019).
} 
Vários estudiosos demonstram que, na França, tradicionalmente, a articulação entre as fontes do direito se faz por meio da aplicação do princípio da norma mais favorável, levand o em conta a hierarquia entre as normas: 1) Código do trabalho, 2) Convenção Coletiva; 3) Acordo de empresa; 4) Contrato de trabalho (CGT-FO, 2018).

Com base no referido princípio e na hierarquia, uma norma inferior (como, por exemplo, o acordo de empresa) não poderia prever disposições menos favoráveis que uma norma no nível superior (código do trabalho e convenção coletiva). A partir das reformas trabalhistas de 2016 e 2017, esse esquema tradicional de articulações entre as normas é colocado em xeque.

A reforma trabalhista de 2016 estabeleceu a possibilidade de negociação das horas suplementares por meio de acordo por empresa. Na nova hierarquia instituída pela referida reforma há três níveis de disposições legais: disposições de ordem pública (nível 1), o campo da negociação coletiva (nível 2); disposições suplementares. As disposições de ordem pública dizem respeito a um conjunto mínimo de direitos que não podem ser derrogados por meio da negociação coletiva. $O$ campo da negociação coletiva diz respeito às diversas disposições das relações trabalhistas que podem ser negociadas através de convenções coletivas ou acordo de empresa. E as disposições suplementares são aplicadas somente na ausência de convenção coletiva ou acordo de empresa. Em relação ao pagamento das horas extras, por exemplo, a nova arquitetura estabelece a seguinte configuração: na ausência de acordo coletivo, o pagamento das horas suplementares deve ser de $25 \%$ nas primeiras 8 horas e $50 \%$ depois deste período. Ressalta-se que, na negociação do valor das horas extras, deve ser respeitado o pagamento mínimo da taxa de majoração de 10\%, conforme mencionamos anteriormente.

Logo, a partir de 2016, no tocante a alguns aspectos do tempo do trabalho, o princ ípio da norma mais favorável e a hierarquia entre as fontes do direito do trabalho passarama ser questionados. Em 2017, a reforma trabalhista do Governo de Macron expandiu essa nova arquitetura para outros domínios das relações do trabalho, redefinindo o enquadramento jurídico da relação entre convenção coletiva (acordo coletivo) e acordo de empresa.

Assim, duas das ordonnances publicadas sob a presidência de Emmanuel Macronse voltam à disciplina da negociação coletiva, as Ord. n 2017-1385 e 2017-1388, ambas de 22 de setembro de 2017. 
Distintamente da reforma trabalhista brasileira, que sobrepôs genericamente o acordo coletivo à convenção coletiva de trabalho, o código francês disciplinou a articulação entre as normas coletivas em três situações: a) uma lista de treze matérias em que a convenção da categoria sempre prevalecerá sobre o acordo de empresa ${ }^{12}$; b) uma lista de quatro matérias em que a convenção da categoria prevalecerá sobre o acordo de empresa na existência de uma cláusula que o preveja expressamente ${ }^{13}$ (clause de verrouillage ${ }^{14}$ ) - e apenas sobre os acordos de empresa que lhe sejam posteriores; c) residualmente, isto é, para todas as demais matérias não elencadas, o acordo de empresa, se existente, prevalecerá sobre a convenção da categoria, independentemente do momento de sua el aboração ou de ser mais ou menos favorável ao empregado.

Com isso, a reforma ampliou consideravelmente as hipóteses em que o acordo de empresa prevalecerá sobre a convenção da categoria, antes restritas às normas sobre duração do trabalho, repouso e feriado. Ademais, sobre todas as outras matérias, a convenção de categoria poderia prever sua primazia sobre o acordo de empresa - o que agora está limitado a quatro matérias, entre elas, a exposição de empregados a fatores de risco profissional (que, antes, figurava entre aqueles temas acerca dos quais a norma da categoria prevaleceria independentemente de previsão, sempre que mais benéfica).

Desse modo, porexemplo, a reforma trabalhista de 2017 institui a primazia do acordo de empresa no tocante à remuneração (prêmios por tempo de serviço, prêmio de férias, indenizações por demissão, indenização por aposentadoria, majoração pelo trabalho noturno, majoração do trabalho aos domingos e em feriados). A referida reforma autoriza, ainda, a edição de plano de demissão voluntária (também chamado de ruptura convencional coletiva) mediante um acordo de empresa.

Desde a Lei de 08/08/2016 (El Khomri), a validade de um acordo de empresa acerca de duração do trabalho, repouso e feriado (hipóteses, como visto, substancialmente ampliadas)

\footnotetext{
12 Registre-se que a previsão não impede a negociação sobre a matéria em nível de uma empresa, mas a norma apenas será aplicada na ausência da convenção da categoria ou se equivalente ou mais favorável ao empregado (L. 2253-1). Desse modo, foram preservadas as disposições de ordem pública (ou seja, as disposições mínimas imperativas).

13 Quais sejam: 1. Prevenção aos efeitos da exposição a fatores de risco profissional; 2. Inserção profissional e permanência no emprego de trabalhadores deficientes; 3. Efetivo a partir do qual os delegados sindicais podem ser designados, seu número e avaliação de sua carreira sindical; 4. Adicionais por trabalho perigoso e insalubre (L. 2253-2).

${ }_{14}$ Cláusula de bloqueio/barreira, em tradução livre.
} 
foi condicionada à sua assinatura: a) poruma ou mais organizações sindicais que houvessem recebido mais de $50 \%$ dos votos no primeiro turno das últimas eleições ao conselho de empresa ou de delegados de pessoal; b) por uma ou mais organizações que houvessem recebido mais que $30 \%$ dos votos na mesma eleição, desde que a norma fosse aprovada por voto da maioria dos empregados.

Contudo, nessa última situação, a consulta aos empregados apenas poderia ser provocada pela entidade sindical. Com a alteração introduzida pela ordonnance, o referendo pode ser provocado pelo próprio empregador.

Conforme Araujo et. al (2017),

este tipo de negociação deve ser feito por meio de referendo (chamado de referendo de empresa) e para ser validada a proposta patronal deve obter a maioria de $2 / 3$ dos votos. Este modo de negociação também é possível no caso das empresas com 11 a 20 trabal hadores que não tenham Comitê Social e Econômico (CSE) ou delegado sindical.

No tocante à facilitação da negociação sem a presença de delegado sindical ou conselho de empresa, o código do trabalho passa a disciplinar três situações, conforme a quantidade de empregados:

a) Nas empresas com menos de 11 funcionários, o empregador poderá propor o acordo diretamente aos empregados, e a proposta será validada com o voto de $2 / 3$ dos empregados, num prazo mínimo de 15 dias após a comunicação;

b) Nas empresas com mais de 11 e menos que 50 empregados, o acordo poderá ser realizado com empregado mandatário (indicado por uma ou mais organizações sindicais da categoria), desde que ratificado com voto da maioria dos empregados; ou com representante eleito do pessoal (membro eleito do Conselho Social e Econômico - $\left(\mathrm{CSE}^{15}\right)$, desde que assinado por membros do CSE representantes da maioria dos votos nas últimas eleições;

\footnotetext{
15 O Comitê Social e Econômico (CSE) foi instituído pelas ordonnances e visa substituir todas as instituições representativas eleitas pelos trabalhadores de uma empresa. Deste modo, até janeiro de 2020, o CSE deve substituir as seguintes instâncias existentes atualmente numa empresa com pelo menos 11 empregados: 0 delegado de pessoal (DP), o comitê de empresa (CE) e o comitê de higiene, segurança e condições de trabalho (CHSCT).
} 
c) Nas empresas com 50 empregados ou mais, a negociação deverá ser feita com representantes eleitos mandatários (indicados por organização sindical e eleitos para a (SE), e, apenas subsidiariamente, com representantes eleitos não mandatários e empregados mandatários não eleitos.

As ordonnances promoveram, também, intervenções voltadas a garantir estabilidade e segurança jurídica às normas coletivas, seja dificultando a sua anulação, seja possibilitando a modulação dos efeitos de uma decisão judicial que o faça.

O novo artigo L. 2262-13 da codificação trabalhista francesa estabelece a presunção relativa (isto é, salvo prova em contrário) de conformidade da norma coletiva à lei. Dessa forma, o ônus de provar a nulidade da norma coletiva é atribuído à parte que a alegar. A seu turno, o artigo L. 2262-14 fixa em 02 meses o prazo para a propositura da ação de nulidade da norma coletiva, após o qual ela se convalidará.

Ademais, ainda que venha a ser reconhecida a nulidade da norma, a reforma positiva cria a possibilidade de que o juiz module os efeitos da decisão, de modo que ela apenas se aplique aos fatos futuros, não prejudicando, inclusive, ações já ajuizadas quanto a fatos anteriores e com os mesmos fundamentos (L. 2262-15).

Por fim, destaca-se que as recentes reformas trabalhistas na França se caracterizam pelo esforço em torno da garantia de existência de uma norma coletiva reguladora das relações de trabalho, o que se verifica, sobretudo, na negociação em nível da empresa. Ao mesmo tempo, verifica-se o receio de que a extensão de normas da categoria a pequenas empresas prejudique o ideal de competitividade perseguido pelas alterações legislativas.

Por força do artigo L. 2242-1, é obrigatória, ao menos uma vez a cada quatro anos, a realização de negociações coletivas em nível de empresa acerca de remuneração, tempo de trabalho, partilha de lucros da empresa, assim como sobre a igualdade profissional entre homens e mulheres e a qualidade de vida no trabalho.

Ainda assim, a ordonnance $n^{\circ}$ 2017-1388 atribui ao Ministro do Trabalho a prerrogativa de negar a extensão de uma norma coletiva da categoria a empresas integ rantes da categoria respectiva, por motivos de interesse geral, sobretudo por atentar excessivamente contra a livre concorrência. Há, inclusive, a possibilidade de que o Ministro, poriniciativa própria ou de organização de empregados ou empregadores, constitua um grupo de especialistas para investigar os efeitos econômicos e sociais da extensão da norma coletiva, ou mesmo que 
submeta a eficácia da norma à superveniência de um acordo de empresa que lhe preveja disposições complementares.

\section{A dinâmica do emprego na França após as reformas trabalhistas}

Nesta seção, busca-se demonstrar alguns efeitos das reformas trabalhistas sobre a dinâmica do emprego na França. Esclarece-se que, em função de algumas mudanças serem muito recentes (2016 e 2017), os impactos ainda não podem ser mensurados, a exemplo dos efeitos das alterações legislativas concernentes à negociação coletiva e a extinção do Comitê de Higiene, Segurança e Condições de Trabalho (prevista para ser concluída até janeiro de 2020). Desse modo, aqui, apresenta-se alguns indicadores sociais das sucessivas alterações legislativas concernentes à pluralização das formas de contratação e jornada de trabalho.

Conforme mencionado anteriormente, a reforma trabalhista era justificada com base em quatro premissas: i) necessidade de manter a atratividade de investimentos das empresas em um ambiente acirrado de concorrência; ii) as alterações da legislação eram (e são) vistas como a principal via de enfrentamento do desemprego; iii) era preciso dar mais autonomia às empresas para modular diversos aspectos da jornada de trabalho, contratação, etc.; iv) buscava-se diminuir a segmentação e heterogeneidade no mercado de trabalho francês, caracterizado pela existência de contratos de trabalho por tempo indeterminado e de duração determinada, levando, assim, à constituição de tipos diferentes de trabalhadores: estabelecidos/estáveis e os outsiders.

Em 2018, a população da França em idade ativa ${ }^{16}$ foi estimada em 29,7 milhões de pessoas, segundo a pesquisa Emploi/lnstituto Nacional de Estatística e Estudos Econômicos da França (INSEE, 2018a) ${ }^{17}$. Em média, neste mesmo período, 26,9 milhões de pessoas encontravam-se empregadas ${ }^{18}$. A taxa de emprego das pessoas entre 15 a 64 anos foi de

${ }^{16}$ Conforme o Insee, "[...] por convenção as publicações estatísticas freqüentemente usam a expressão "França inteira" ou "França" para designar o grupo geográfico incluindo a França metropolitana e os 5 departamentos ultramarinos de Guadalupe, Martinica, Guiana Francesa, Reunião e Mayotte." Fonte: Fonte: https://www.insee.fr/fr/metadonnees/definition/c16g6.

17 A pesquisa Emploi do Instituto Nacional de Estatística e Estudos Econômicos da França (Insee) tem por objetivo analisar a situação das pessoas no mercado de trabalho (emprego, desemprego, condições de trabalho, etc.) e desde 2003 tornou-se contínua, passando a ser realizada semanalmente.

${ }^{18}$ A pesquisa Emploi adota o conceito de empregados da OIT, qual seja: empregado é aquele que exerceu ao menos uma hora de trabalho remunerado no curso da semana dada. 
$64,7 \%$ em 2017. Os dados do Insee revelam, ainda, que a referid a taxa ficou um pouco inferior àquela encontrada antes da crise econômica de 2008.

Embora seja recorrente o argumento de que o enfrentamento ao desemprego passa necessariamente pela reforma trabalhista, as inovações legislativas neste campo não cumpriram a promessa de resolver a questão do desemprego na França (SUPIOT, 2016; EYDOUXe FRETEL, 2016, etc.).

Deste modo, em 2017, existiam 2,8 milhões de desempregados ${ }^{19}$ na França (incluindo os departamentos ultramarinos, com exceção de Mayotte), segundo a pesquisa Emploi/Insee (2018a). Observa-se que, a partirda crise de 2008, o desemprego cresce de forma constante até 2015, atingindo 10,4\% da população economicamente ativa (ou seja, um pouco mais de 3 milhões de pessoas). Em 2016, a taxa de desemprego reduziu um pouco em relação ao ano anterior (10,1\%). Em termos de números absolutos, essa pequena queda revelou que 80 mil pessoas saíram da condição de desempregados. E finalmente, em 2017, a taxa de desemprego alcança seu patamar mais baixo desde a crise econômica de 2008 (9,4\%). Convém destacar que, apesar da redução do desemprego, em 2017, 1,2 milhões de desempregados estavam há mais de um ano buscando trabalho (EMPLOI/INSEE, 2018a). Os dados demonstram, ainda, que os jovens (pessoas de 15 a 29 anos) representam $32,8 \%$ do total dos desempregados de longa duração ${ }^{20}$.

No tocante à diversificação das formas de contratação, Fretel (2016) conclui que as inovações legislativas levaram à institucionalização da precarização do trabalho. Conforme a referida autora, essa precarização se observa, em primeiro lugar, nas franjas do emprego assalariado, com o aumento lento e constante dos empregos de vínculos instáveis ou temporários (contrato de curta duração, temporário, aprendiz, etc.) e no número de desempregados. Todavia, Fretel (2016) afirma que a precarização também atinge os trabalhadores em empregos considerados estáveis por meio de dois mecanismos: i) a

\footnotetext{
19 O Instituto Nacional de Estatística e Estudos Econômicos da França (Insee) adota o conceito de desempregado proposto pela OIT, a saber: considera-se como desempregado a pessoa em idade de trabalhar (15 anos ou mais) que responde simultaneamente às três condições mencionadas a seguir: a) estar sem emprego, isto é, não ter trabalhado nem que seja uma hora na semana de referência da pesquisa; b) estar disponível para o trabalho em 15 dias; c) ter procurado ativamente um emprego nas últimas 4 semanas (incluindo a semana de referência) ou ter encontrado um trabalho que comece no prazo de até 3 meses.

20 O desemprego de longa duração é definido pela busca de trabalho a mais de um ano.
} 
rotatividade no emprego ou estabilidade relativa, tendo em vista que $1 / 3$ dos contratos em CDI são rompidos antes de um ano; ii) aumento do trabalho port empo parcial.

Em 2017, 74,8\% da população assalariada possuía o contrato de trabalho por tempo indeterminado (CDI). Contudo, as formas mais precárias de emprego (contrato de duração determinada - $C D D$, contrato de trabalho temporário e aprendizagem) responderam, no mesmo perío do por 13,6\% das contratações entre os ocupados, segund o o Instituto Nacional de Estatística e Estudos Econômicos da França (INSEE, 2018a).

No tocante ao tempo parcial, constata-se que, na França ${ }^{21}$, em 2017, 18,8\% dos ocupados de 15 anos ou mais trabalhavam em tempo parcial. O tempo parcial é maior entre as mulheres (30\% dos ocupados) do que entre os homens $(8,3 \%)$. Nesse mesmo período, 0 contingente de pessoas alocadas em subemprego ${ }^{22}$ atingiu o patamar de 1,6 milhões de pessoas, ou seja, 6,1\% das pessoas empregadas trabalhavam menos horas do que desejariam (INSEE, 2018a).

Os dados do Insee revelam que, na França, de 1982 a 2017, as formas de contratação mais precárias (representadas pelos empregos de curta duração, isto é, contratos de trabalhos de duração determinada, contratos sazonais, temporário e aprendiz) têm uma trajetória ascendente, aumentando ano após ano sua participação no mercado de trabalho francês: Se em 1982, as modalidades precárias de contratação respondiam por 5,3\% do emprego, uma década depois (1992), cresceram 2,2 pontos percentuais a participação no emprego, alcançando seu patamar mais elevado em 2017, quando o somatório das modalidades contratuais em tela registrou $13,6 \%$.

No tocante ao contrato de trabalho temporário (CTT), Lapoire (2011) verificou que, com a legalização dos CTT, houve um aumento das agências de trabalho temporário na França, passando de 1.965 estabelecimentos em 1972 para 3.600 agências em 2004. Ainda segundo a autora, tais agências conseguiram colocação de trabalho para dois milhões de pessoas em 2004, representando 3,2\% da atividade assalariada no referido ano. Dados mais

\footnotetext{
${ }^{21}$ Neste caso, trabalha-se com o seguinte recorte geográfico França metropolitana e os departamentos ultramarinos de Guadalupe, Martinica, Guiana Francesa, Reunião, com exceção de Mayotte.

22 O Instituto Nacional de Estatística e Estudos Econômicos da França (Insee) adota o conceito subemprego proposto pela OIT. Assim, "o subemprego refere-se a pessoas que têm um emprego a tempo parcial, que querem trabalhar mais e que estão disponíveis para o fazer, quer estejam à procura de emprego ou não. Também subempregados são pessoas que trabalharam involuntariamente menos que o habitual (desemprego parcial, etc.)". (Insee, 2019).
} 
atuais do Insee revelam que, em 2016, essa modalidade contratual representava 2,6\% do total das contratações no mercado de trabalho francês.

Um estudo conduzido pela Direção de pesquisas, estudos e estatísticas (DARES) do Ministério do Trabalho da França (2018) indica que a taxa de rotatividade de mão-de-obra aumentou consideravelmente em 25 anos, passando de 29\% em 1993 para 96\% em 2017. Esse crescimento da rotatividade se dá fundamentalmente pelo desenvolvimento dos CDD muito curtos (ou seja, contratos com duração inferior a um mês), enquanto o uso de CDI permanece relativamente estável.

Sobre este aspecto, o referido estudo revela, também, que entre os Contratos de Duração Determinada (CDDs), a proporção de contratos de menos de um mês aumentou substancialmente, passando de 57\% do total dos CDDs em 1998 para 83\% em 2017. Destes, os "CDDs de um dia" passaram de 8\% em 2001 para 30\% em 2017. Neste sentido, longe de cumprir a promessa de diminuição da segmentação do mercado de trabalho, as inovações legislativas concernentes à contratação revelam a constituição de uma dualização do mercado de trabalho francês, entre empregados estáveis (em contratos por tempo indeterminado) e os demais trabalhadores em CDD ou CTT; dentre estes últimos, há uma parcela significativa de trabalhadores em contratos de curtíssima duração (DARES/MINISTÉRIO DO TRABALHO, 2018).

No que diz respeito à jornada de trabalho, as inovações legislativas resultaram, de um lado, na redução da duração legal da jornada de trabalho, culminando na definição atual de 35 horas semanais (ou 1.607 horas anuais) e, de outra parte, ocorreu a introdução de dispositivos de ajustes da jornada de trabalho, notadamente no que concerne à utilização do trabalho portempo parcial e à ampliação das possibilidades de utilização das horas extras (ou suplementares) pormeio de acordo porempresa (conforme instituído pela reforma de 2017).

Segundo os dados do Insee (2018b), no período de 1950 e 2016, há uma diminuição de $23 \%$ do tempo anual de todos os empregados na França. Registra-se que, apesar de essa tendência de redução do tempo ser observada desde meados dos anos 1960, é fundamentalmente a partir de 1965 e até 1982 que uma parte significativa do declínio ocorreu, em função das seguintes inovações legislativas: $4^{\mathrm{a}}$. Semana de férias pagas em 1968 e 39 horas semanais em 1981. Em 1990, as horas de trabalho caíram novamente com o acrescimento do trabalho em tempo parcial e, posteriormente, com a regulamentação das 
35 horas. Essa tendência de queda é interrompida em 2002, porconta do aumento das horas suplementares (extras).

Sobre este aspecto, Michel Miné (2017) chama atenção para a existência de uma desigualdade na distribuição do tempo do trabalho, que se expressa na seguinte disjuntiva: de um lado, as mudanças legislativas favoreceram um aumento do tempo de trabalho para as pessoas que trabalham em tempo integral (por conta, fundamentalmente, da realização de horas suplementares); ao passo que as pessoas que trabalham em tempo parcial e os desempregados são excluídos deste aumento da jornada de trabalho.

No tocante às horas suplementares, os dados do Dares/Ministério do trabalho da França revelam que, no primeiro trimestre de 2019, o número médio de horas extras do trabalhador em tempo integral é de 10,4 horas, representando um aumento de 9,3\% do número de horas extras trabalhadas no mesmo período do ano anterior. As empresas com 20 a 49 empregados foram as que mais contribuíram para o crescimento das horas suplementares. No que concerne ao setor de atividade, o ramo da construção civil concentra o maior número de horas suplementares trabalhadas, com uma média de 22,0 horas extras por trabalhadorem tempo integral no primeiro trimestre de 2019.

Por outro lado, no primeiro trimestre de 2019, 1,4 milhões de pessoas encontravamse subempregadas, isto é, trabalhando menos horas do que precisam/desejam. Deste total de subempregados, $96 \%$ são de trabalhadores em tempo parcial. Em suma, os dados sugerem que há uma distribuição desigual da jornada de trabalho em função do tipo de contrato de trabalho (INSEE, 2019).

\section{Considerações finais}

As reformas trabalhistas realizadas na França e demais países europeus, por si sós, não foram capazes de alavancar o crescimento e solucionar o desemprego nos países da região, particularmente da França. Deste modo, no caso francês, a taxa de desemprego cresceu de forma constante no período de 2008 a 2015, quando alcançou seu ápice ao registrar 10,4\%, atingindo, portanto, mais de 3 milhões de pessoas. A partir de 2016, verificase a queda pequena e constante do desemprego (INSEE, 2018a). Apesar da redução do desemprego, em 2017, 1,2 milhões de pessoas vivenciavamo desemprego de longa duração. 
De outra parte, as sucessivas mudanças legislativas concernentes à contratação não foram capazes de cumprira promessa de acabar com a segmentação do mercado de trabalho francês. Ao contrário, os indicadores sociais apresentados revelam um aprofundamento das formas de mercantilização da mão de obra, criando um fosso entre trabalhadores de contrato de duração indeterminada e os contratos precários, designados pela literatura francesa de contratos atípicos (contratos de duração determinada, temporários e aprendiz). Em relação aos CDDs, chama atenção o crescimento dos contratos de curtíssima duração (menos de um mês), que têm produzido efeitos negativos sobre o aumento da taxa de rotatividade da mão de obra na França, conforme mencionamos acima.

Soma-se a esta situação, a existência de trabalhadores de tempo integral (35 horas semanais) e os trabalhadores de tempo parcial. Neste último segmento, é grande o número de trabalhadores que desejam trabalhar mais horas e não conseguem: 1,4 milhões no primeiro trimestre de 2019 (INSEE, 2019).

Embora ainda não seja possível conhecer a totalidade dos impactos das reformas trabalhistas de 2016 e 2017 (especialmente no tocante à redução das instâncias de representação de pessoal, saúde e segurança no trabalho e negociação coletiva) os indicadores sociais apresentados corroboram, de certa forma, as pesquisas de vários autores franceses que afirmam que a flexibilização da legislação trabalhista levou à institucionalização da precarização social do trabalho. Tal precarização tem como eixos a intensificação das formas de mercantilização do trabalho e o descarte do direito do trabalho (DRUCK, 2013).

É neste sentido que a contraposição dos indicadores sociais aos jurídicos e às narrativas que justificaram a modificação do marco legal trabalhista na França reflete o que Dardot e Laval (2019) intitulam "a crise como forma de governo", na medida em que o neoliberalismo se afigura como um modelo retroalimentado pelas suas próprias crises e que, em lugar de questionar as causas reais de sua emergência, apresenta, sistematicamente, respostas que apenas aprofundam a lógica que as produziu - instituindo, de forma correlata, para o Direito do Trabalho, uma racionalidade jurídica de contingências.

Ressalta-se, ainda, que o processo de institucionalização da precarização do trabalho está em consonância com a racionalidade neoliberal, que estabelece uma nova política de Estado que tem na desregulamentação dos direitos sociais (do trabalho e da previdência, principalmente) e na promoção do direito privado um dos seus eixos (DARDOT e LAVAL, 
2016). Assim, no contexto de ascensão do neoliberalismo, as sucessivas mudanças da legislação trabalhista na França têm resultado, porum lado, na desconstrução do estatuto do assalariado; e de outra parte, regulamentado as relações de trabalho sob o paradigma do direito privado e sua lógica negocial.

\section{Referências}

ABAUZIT, Richard; FILOCHE, Gérard. CommentrésisterauxloisMacron, El Khomri e CIE. Paris: Le vent se leve, 2016.

ARAUJO, M. A. de; DUTRA, R. Q.; JESUS, S. C. S. de. Neoliberalismo e flexibilização da legislação trabalhista no Brasil e na França. Salvador, Caderno CEAS, n. 242. 2017.

Disponível em:

$<$ https://cadernosdoceas.ucsal.br/index.php/cadernosdoceas/article/view/401 >. Acesso: 20 de maio de 2018.

BADINTER, Robert; LYON-CAEN, Antoine. Porune "Declaration des droit du travail". Le Monde, 2015. Disponível em: <https://www.lemonde.fr/societe/article/2015/06/15/pour-unedeclaration-des-droits-du-travail_4654173_3224.html> Acesso em: 05/08/2019.

CGT-FO. Les conséquences de la loi travail de 2016 et des ordonnances de 2017. Paris: février, 2018. Confédération générale du travail-Force ouvrière - CGT-FO. Disponível em:<https://6o.force-ouvriere.org/IMG/pdf/18-40-mailly-

fiches pratiques loi travail et ordonnances 2017.pdf. Acesso em: 21/04/2018.

DARDOT, Pierre; LAVAL, Christian. A nova razão do mundo: ensaio sobre a sociedade neoliberal. Trad. ECHALAR, Mariana. São Paulo: Boitempo, 2016.

DARDOT, Pierre; LAVAL, Christian. Anatomía Del nuevo neoliberalismo. Viento sur, n' 164 , año XXVII, Jun. 2019, p. 5-16. Disponível em:

$<$ http://cdn.vientosur.info/VScompletos/vs 0164.pdf>Acesso em: 05/08/2019.

DARES/MINISTÈRE DU TRAVAIL DE FRANCE, Les heures supplémentaires. Les séries trimestrielles. Paris, 19/7/2019. Disponível em: https://dares.travail-emploi.gouv.fr/daresetudes-et-statistiques/statistiques-de-a-a-z/article/les-heures-supplementaires\#. Acesso em: 31 de julho de 2019.

DARES/MINISTĖREDU TRAVAIL DE FRANCE. CDD, CDI: comment évoluent les embauches et les ruptures depuis 25 ans?, juin/2018. Disponível em: https://dares.travailemploi.gouv.fr//MG/pdf/2018-026v2.pdf. Acesso em: 30 de julho de 2019.

DELGADO, Maurício Godinho. Curso de Direito do Trabalho. 18. ed. São Paulo: LTr, 2019. 
DRUCK, G. Precarização social do trabalho. In: IVO, A. B. L. (coord). Dicionário temático desenvolvimento e questão social: 81 problemáticas contemporâneas. São Paulo: Annablume; Brasília: CNPq; Salvador: Fapesb, 2013, p. 373-380.

ESPINA, Álvaro. La reforma de laley de trabajoen Francia: un caso de estúdio. Boletín económico de ICE, Información Comercial Española, ISSN 0214-8307, No 3076 (Del 1 al 30 de Junio 2016), 2016, págs.15-36. Disponível em:

https://dialnet.unirioja.es/servlet/articulo?codigo=5767334. Acesso em: 05/08/2019.

EYDOUX, Anne; FRETEL, Anne. Réformes Du marche du travail - Des reformes contre l'emploi, jan. 2016. Disponível em: http:// www.atterres.org. Acesso em: 10/7/2016.

FRETEL, Anne. La reforme du droit du travail: le nouvel impératiféconomique. Revue Française de Socio-Économie, n. 16, 2016, p. 5 - 18.

HARVEY, D. A condição pós-moderna. São Paulo: Loyola, 1992.

INSEE. Une phottographie du marche du travail em 2017. Paris, Insee Première, n. 1694, avril 2018a.

INSEE. Durée et organisation du temps de travail. Paris, Insee références, 2018b.

INSEE. Durée et organisation du temps de travail. Paris, Insee références, mars 2019. Disponivel em: https://www.insee.fr/fr/statistiques/3676634? sommaire=3696937. Acesso em: $31 \mathrm{de}$ julho de 2019.

LAPOIRE, M. Travail temporaire, marché permanent. Quand les contraintes régulamentaires génèrent des échanges. Droit et societé, n. 77, 2011, p. 19-37.

MINÉ, Michel. Quand le droit favorise l'augmentation et la flexibilité du temps de travail. La nouvelle revue du travail, 2017. Disponível em: http://journals.openedition.org/nrt/3234. Acesso em: 10 de outubro de 2018.

SCHÖMANN, Isabelle. Réformesnationalesdudroitdutravailentemps de crise:

Bilanalarmantpourlesdroitsfondamentaux et ladémocratieenEurope.

Revuelnterventionséconomiques [Enligne], 52 | 2015, mis enlignele 01 mars 2015, cons ultéle 18 décembre 2017. Disponível em: http://journals.openedition.org/interventionseconomiques/2437. Acesso em: 05/08/2019.

SUPIOT, Alain (coord). Au-dela de l'emploi: lesvois d'une vraie reforme dudroitdutravail. Paris: Flammarion, 2016.

WEBER, Max. A ética protestante e o espírito do capitalismo. Trad. Pierucci, Antônio Flávio. São Paulo: Companhia das Letras, 2004.

WILLEMEZ, Laurent. Le travail dans son droit. Sociologie historique du droit du travail en France (1892-2017). Paris: L.G.D.J, 2017. (Collection: Contextes). 


\section{Dados dos autores}

\section{Selma Cristina Silva de Jesus}

Pós-doutorado em sociologia pela Université Paris Nanterre. Professora da Faculdade de Educação e PPGCS da Universidade Federal da Bahia - UFBa. E-mail: selmacsj@gmail.com

Douglas Mota Oliveira

Graduando em Direito pela Universidade Federal da Bahia - UFBa. E-mail: douglasmota.oliveira@gmail.com 